\title{
A NEW INTERFERENCE APPARATUS FOR TESTING HAEMACYTOMETERS
}

\author{
By C. G. Peters and B. L. Page
}

\section{ABSTRACT}

Haemacytometers, or counting chambers, which are glass plates having a polished rectangular strip between, and a specified distance below, two polished or matt surfaces that support the cover glass, are used in the diagnosis of certain diseases for determining the number of corpuscles per cubic millimeter in the blood. The extensive use of haemacytometers and the importance of having them very accurate, in order to insure a reliable count, have created a need for rapid and precise methods for testing their dimensions. Since the micrometric instrument commonly used to measure the depths of chambers is subject to appreciable errors, a more accurate instrument based upon the principle of the interference of light waves was, therefore, designed and constructed. With this interference apparatus the planeness errors of cover glasses and the planeness and parallelism errors of the supporting and central strips of the chambers can be readily measured with an uncertainty of not more than a few hundredths of a micron. A comparative test of the two instruments showed that with the micrometric instrument about five minutes were required to make the measurements of the depth, and the error of measurement was about $1 \mu$ (micron), while with the new interference instrument one minute was required to make the measurements and the error of measurement was not more than $0.2 \mu$

\section{CONTENTS}

I. Introduction

II. Description of haemacytometers _...

III. Specifications for certified haemacytometer chambers_...-_..... 223

IV. Description of micrometer apparatus._._._._._._._. 224

V. Interference apparatus and method........... 225

VI. Test of the cover glasses_._._.

VII. Test for planeness and parallelism of the central and supporting

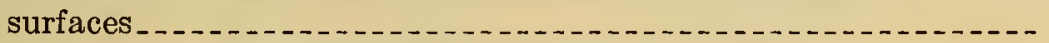

VIII. Test of the two instruments

IX. Conclusion

\section{INTRODUCTION}

Haemacytometers, or counting chambers, which are glass plates having a polished rectangular strip between, and a specified distance below, two polished or matt surfaces that support the cover glass, are used in the diagnosis of certain diseases for determining the number of corpuscles per cubic millimeter in the blood. The extensive use of haemacytometers and the importance of having them very accurate, in order to insure a reliable count, have created a need for more rapid and precise methods for testing their dimensions in 
both the certifying laboratory and the manufacturing plant. The Bureau of Standards has for several years tested haemacytometers and certified those which conformed to the approved specifications. At the present time the tolerance allowed in the depth is $0.002 \mathrm{~mm}$ $(2 \mu)$ for chambers $0.1 \mathrm{~mm}$ deep. In testing the depth, an apparatus having a scale and a micrometer microscope for a measuring element has been used. The errors of the scale intervals and micrometer screw, together with the possible variation in the illumination of the scale and cross wires produced errors in the measurements, which in some cases were as large as $1.0 \mu$. Furthermore, the instrument required about 10 minutes to test each chamber; and the work was difficult and fatiguing when continued over a long period of time. We have, therefore, designed and constructed a more sensitive apparatus, based upon the principle of the interference of light waves, having negligible instrumental errors, and with which a chamber can be measured in one or two minutes with an uncertainty of not more than $0.2 \mu$. A description of the new apparatus and the results of comparative tests of the sensitivity and reliability of both instruments are presented in this paper.

\section{DESCRIPTION OF HAEMACYTOMETERS}

Four moats represented by $A$, Figure 1 , are cut across the glass plate, which is about $6 \mathrm{~cm}$ long, $3 \mathrm{~cm}$ wide, and $0.5 \mathrm{~cm}$ thick, leaving
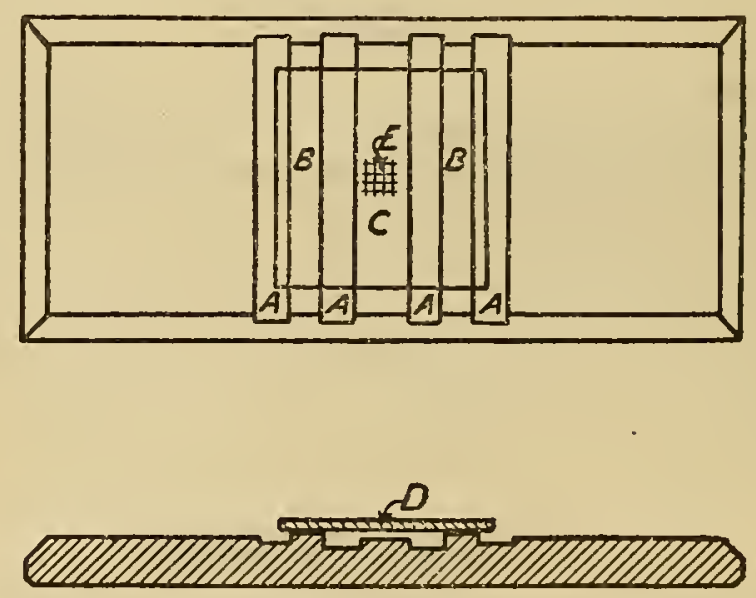

FIG. 1.-Haemacytometer and cover glass

three strips $B, B$, and $C$. The central strip $C$ is ground down below the upper surface of the plate and polishod as nearly optically plane as possible. The two strips $B, B$, one on each side of $C$ are ground or polished until they lie in a plane which is parallel to and $0.1 \mathrm{~mm}$ above $C$. Near the center of the surface $C$ are ruled lines which make a $1 \mathrm{~mm}$ square, $E$, subdirided into 400 equal squares, shown on an enlarged scale in Figure 2. When the cover glass $D$ (fig. 1) 
is brought into contact with the two supporting surfaces $B, B$, a space $0.1 \mathrm{~mm}$ thick is formed between the lower surface of the cover glass and the surface of the central strip $C$. At the ruled portion of $C$, volumes $0.1 \mathrm{~mm}$ deep and from $0.0025 \mathrm{~mm}^{2}$ to $1 \mathrm{~mm}^{2}$ in cross section are then defined. From counts of the number of corpuscles in these volumes the number per cubic millimeter can be computed.

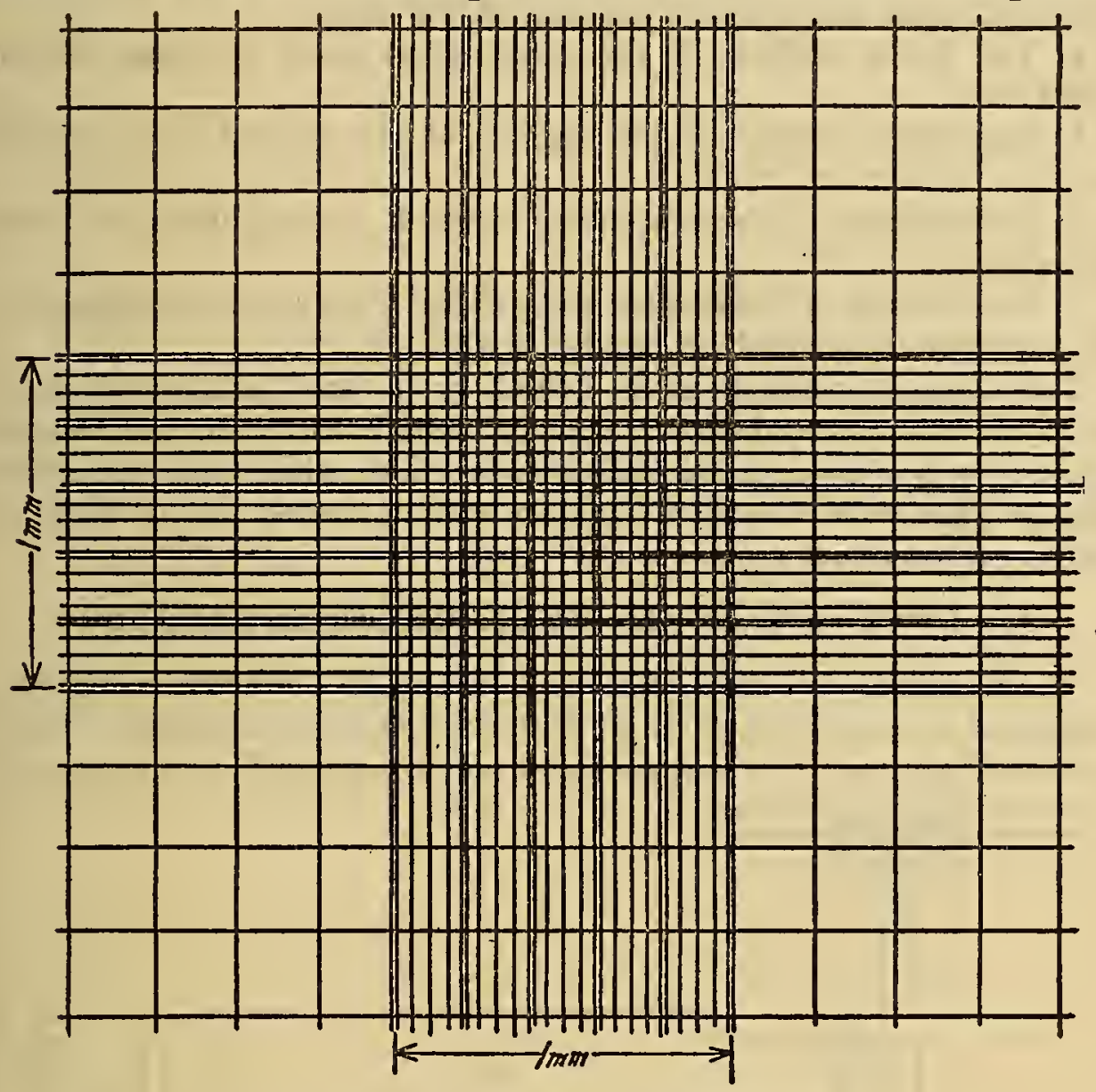

FIG. 2.-Rulings on the central strip

In order that the count be reliable it is important that the dimensions of the ruled square $E$ and the depth of the space be accurate.

\section{SPECIFICATIONS FOR CERTIFIED HAEMACYTOMETER CHAMBERS}

To fulfill the requirement of accurate dimensions, haemacytometers should conform to the following specifications, proposed by the Bureau of Standards:

The first four have been accepted, while the last three, which are equally important, have not yet been adopted by manufacturers and physicians. 
1. All glass used in chambers shall be clear, colorless, and free from bubbles and istrias.

2. The error in the dimensions of the ruled millimeter square $E$ shall not exceed 1 per cent $(0.01 \mathrm{~mm})$.

3 . The error in the depth of the chamber, measured from the plane of the supporting surfaces $B, B$ to the center of the millimeter square $E$, shall not exceed 2 per cent $(0.002 \mathrm{~mm})$.

4. The lower surface of the cover glass shall be plane within $0.002 \mathrm{~mm}$.

5. The ruled portion of the surface of the central strip $C$ shall be plane within ***.

6. The surfaces of the supporting strips $B, B$ shall lie in the same plane within * **.

7. The surface of the central strip $C$ and the plane of the supporting surfaces $B, B$ shall be parallel within ****

The second requirement is tested by a line-standard method. Only the third requirement can be tested with the micrometer apparatus described in the following section, while with the interference apparatus, haemacytometers can be tested for all requirements except No. 2.

\section{DESCRIPTION OF MICROMETER APPARATUS}

The essential parts of the micrometric apparatus shown in Figure 3 consist of a cylindrical anvil $H, H$, a micrometer microscope $M$ and a vertical plunger $P$, which carries a contact point $F$, and a scale $S$.

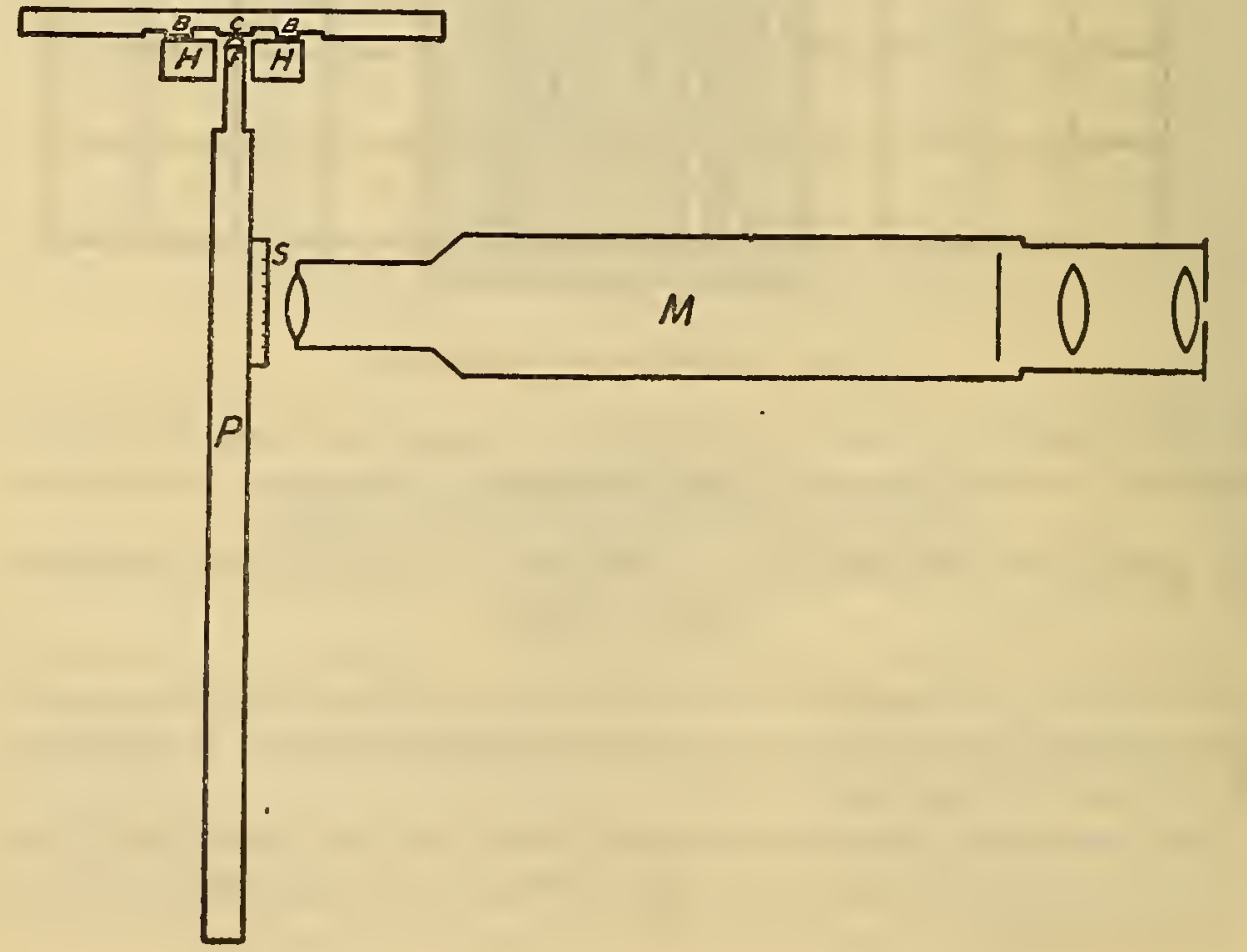

FIG. 3.-Essential parts of the micrometric apparatus 
Scientific Papers of the Bureau of Standards, Vol. 20

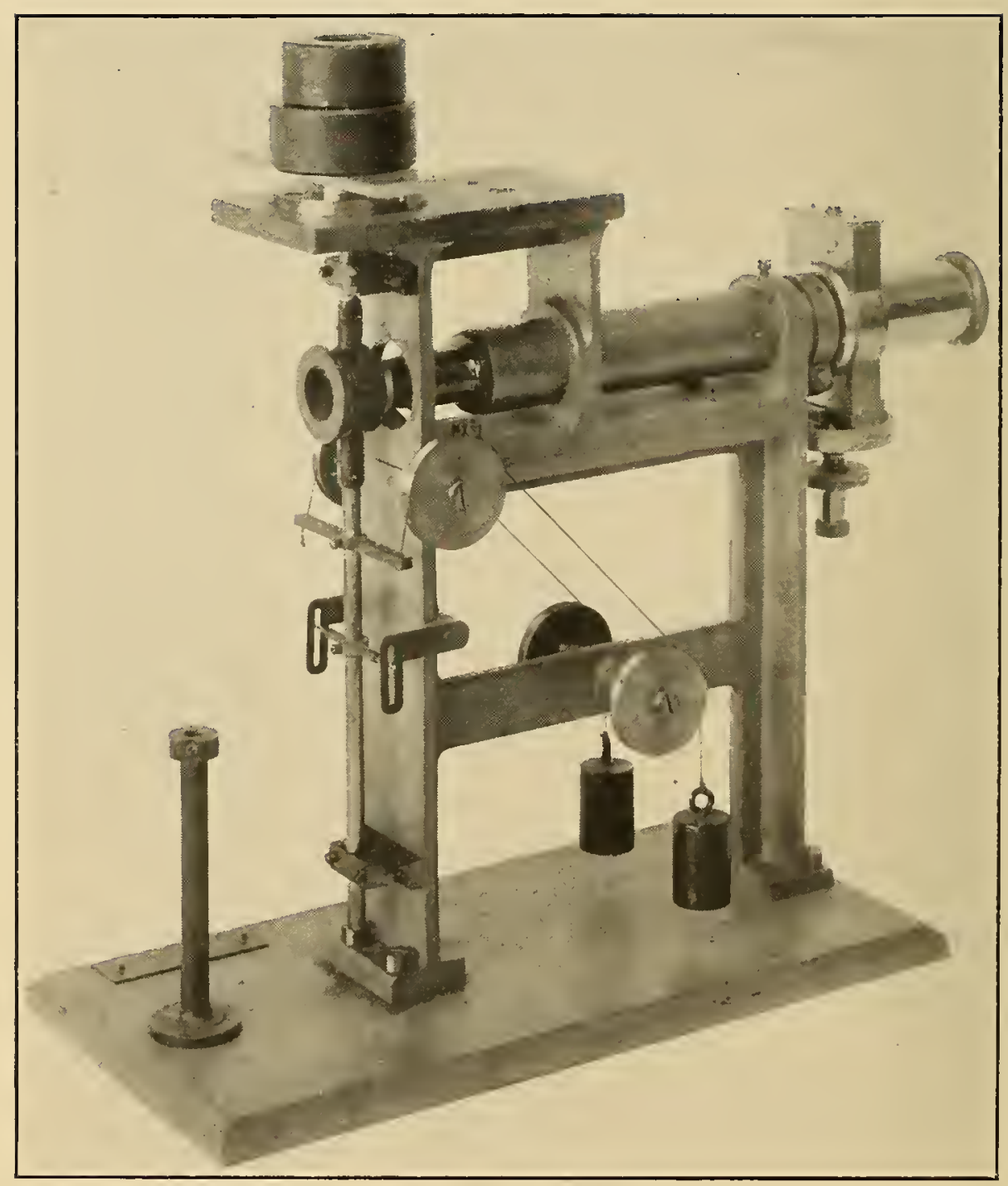

FIG. 4.-Micrometric àpparatus 
The upper surface of the hardened steel anvil $H, H$ is polished and plane. The plunger $P$, which passes through close-fitting bearings and the central opening in the anvil, is held up by a system of weights and pulleys. The scale $S$ has lines $0.1 \mathrm{~mm}$ apart upon which the microscope is focused. A view of the assembled instrument is shown in Figure 4.

In making the measurements the plane surface of a plate is placed in contact with the anvil surface and the contact point of the plunger. The zero position of the contact point is then located by taking the mean of four settings of the micrometer cross wires on one of the lines of the scale. An inverted chamber is then substituted for the plate. The supporting strips $B, B$ (fig. 1 ) are brought into contact with the anvil, the ruled portion $E$ of the central strip $C$ touching the contact point. A small weight is placed on the plate or chamber to insure constant pressure. A second position of the contact point is located from the mean of four more micrometer settings on a second line of the scale. The depth of the chamber is computed from the two mean values of the micrometer readings, the corrected interval between the two lines of the scale, and the screw value of the micrometer.

\section{INTERFERENCE APPARATUS AND METHOD}

The interference apparatus for measuring the depth of haemacytometers shown in Figure 5 consists of two interferometer plates $V$

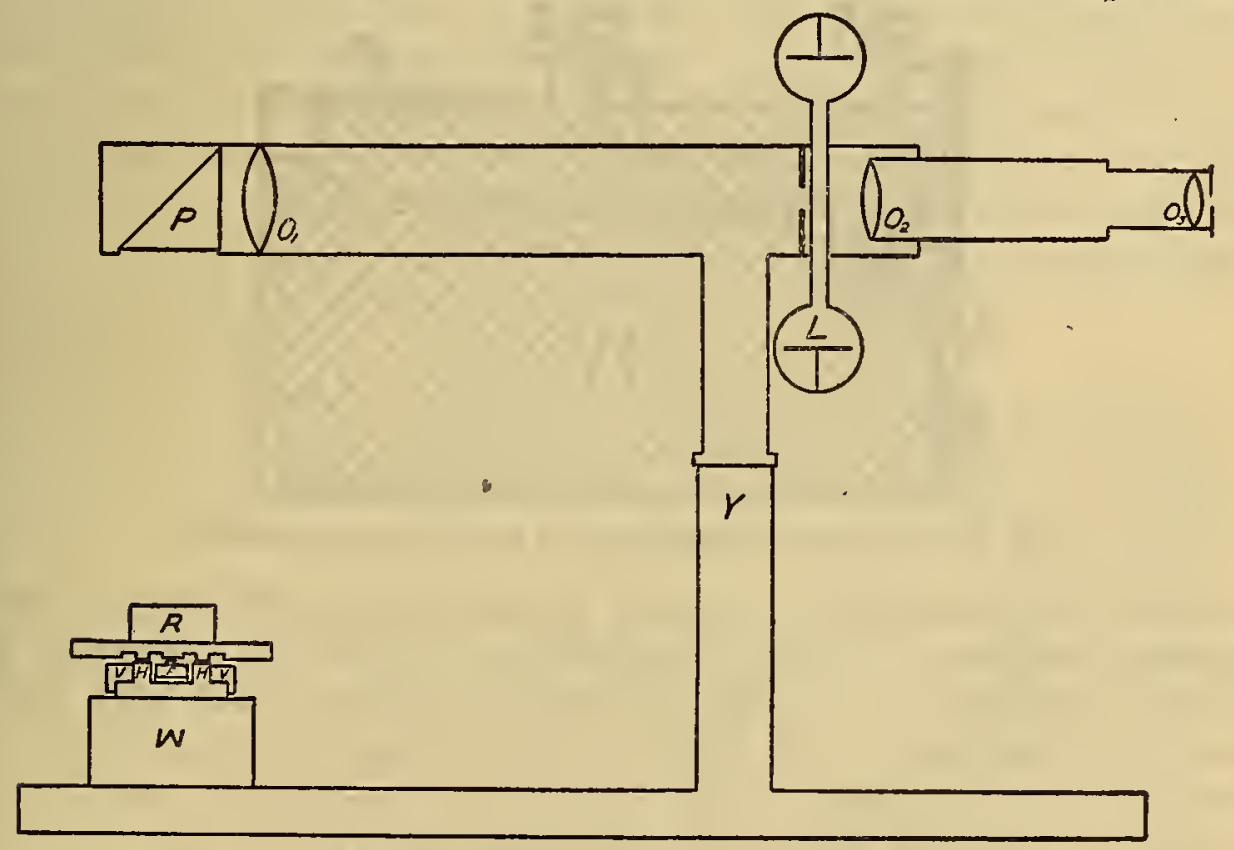

FIG. 5.-New interference apparatus

and $W$, an anvil $H, H$, and an optical arrangement for illuminating and viewing the interference fringes. The light from the helium 
lamp $L$ made parallel by the lens $O_{1}$, is reflected by the total reflecting prism $P$ down to the interferometer plates $V$ and $W$. The rays reflected from the adjacent surfaces of the plates are brought to a focus by the lenses $O_{1}$ and $O_{2}$ in the principal focal plane of $O_{2}$, and images of the interference pattern and reference marks on the plate $V$ are viewed with the eyepiece $O_{3}$. This arrangement can be rotated about the vertical support $Y$, and used to test the planeness
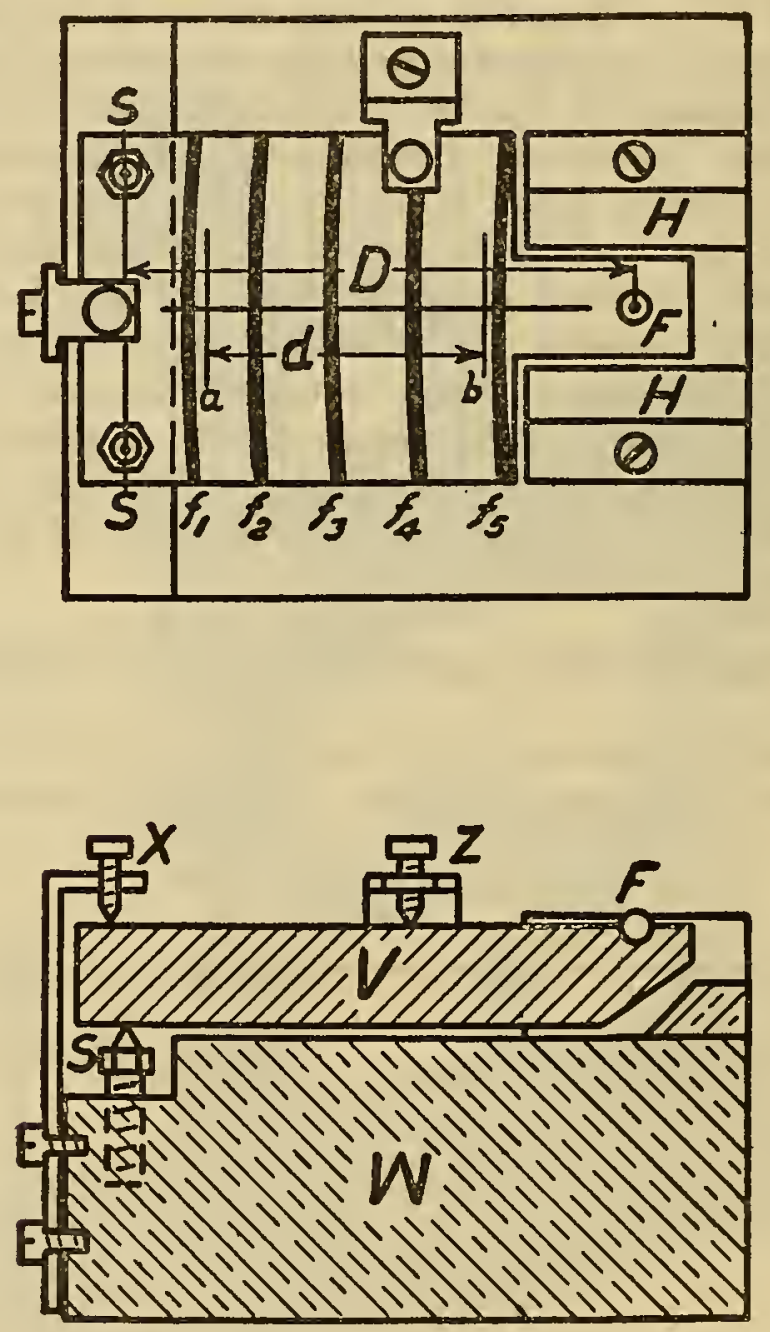

FIG. 6.-Measuring element of the interference apparatus

of the cover glass surfaces and the planeness and parallelism of the chamber surfaces. A more detailed view of the interferometer is shown in Figure 6. The upper surface of the hardened steel base plate $W, 6 \mathrm{~cm}$ long, $5 \mathrm{~cm}$ wide, and $2 \mathrm{~cm}$ thick, is polished plane within $0.02 \mu$. A strip $1.0 \mathrm{~cm}$ wide and $0.5 \mathrm{~cm}$ deep is cut across one end of the block and two holes $2.5 \mathrm{~cm}$ apart are tapped into the recess. Into these holes are fitted the screws $S, S$ having conical tops.

The upper and lower surfaces of the anvil $H, H$, which is a hardened steel block $3 \mathrm{~cm}$ long, $2 \mathrm{~cm}$ wide, and $1 \mathrm{~cm}$ thick, are polished plane 
and parallel. Three strips are cut across the anvil leaving the two parallel contact surfaces $H, H$, which are $0.5 \mathrm{~cm}$ in width, $2.0 \mathrm{~cm}$ in length, and $1.0 \mathrm{~cm}$ apart. The lower surface of the anvil and the upper surface of the base block are wrung into contact and the two pieces fastened together with two screws, making the base block and anvil practically a solid piece with the contact surfaces of the anvil lying in a plane parallel to, and $1.0 \mathrm{~cm}$ above, the surface of $W$.

The upper interferometer mirror $V$, which is a glass plate $0.9 \mathrm{~cm}$ thick with both surfaces polished true plane, has a steel ball $F$ cemented into the tongue which projects about $15 \mathrm{~mm}$ from the body of the plate. The ball which protrudes about $0.5 \mathrm{~mm}$ above the upper surface of the plate forms the contact point.

The upper plate $V$ rests upon the conical points of the screws $S, S$ and is held up against the stop $Z$ by the adjustable spring $X$. The points of the screws are set in a groove cut in the lower surface of the plate thus assuring a constant distance $D$ from the contact point $F$ to the line $S, S$. The two screws are so adjusted that when the contact point $F$ is $0.1 \mathrm{~mm}$ above the plane of the contact surfaces $H, H$, the lower surface of the plate $V$ is exactly parallel to the upper surface of the base block $W$ making a plane parallel space about $0.5 \mathrm{~mm}$ thick between the plates. The light from the lamp $L$ made parallel by the lens $O_{1}$ (fig. 5), falling on the upper surface of this space is in part reflected and the rest transmitted to the lower surface where again part of the light is reflected. Between these two reflected wave trains, interference takes place, and since they return along the perpendicular to the surfaces, a condition which holds over the entire field of view, the difference in path of two interfering trains ( $n$ the number of waves times the wave length $\lambda$ ) is equal to the double thickness $2 t$ of the space; that is, $n \lambda=2 t$. Since $t$ is constant over the entire space, $n$ the order of interference is also constant at every position, therefore the space appears uniformly illuminated.

If now the plate $V$ is rotated about the line $S, S$, causing the contact point $F$ to move up or down, the space between the plates becomes wedge shaped, with the intersection of its surfaces parallel to $S, S$. Wherever $2 t$ is equal to some whole number of wave lengths interference takes place and straight dark bands parallel to $S, S$, appear across the face of the wedge. In Figure $6, f_{1}, f_{2}, f_{3}$, etc., represent these bands. The band $f_{1}$ shows that along that line the distance down and back between the plates is some whole number of wave lengths. At a wider part of the wedge another line $f_{2}$ is reached where twice the distance between the plates is one wave length greater than at $f_{1}$. Similarly along $f_{3}$ the distance is two wave lengths greater than at $f_{1}$, etc. Starting from $f_{1}$ each successive band denotes that the separation of the two plates has increased by one-half the wave $40225^{\circ}-25-2$ 
length of the light, therefore the total number of bands between $S, S$, and $F$ multiplied by one-half the wave length of the light used $\left(\frac{\lambda}{2}\right)$ gires the difference in separation of the plates at $F$ and $S, S$, or the difference in elevation of the final and zero positions of $F$. As it is difficult to determine the number of bands between $F$ and $S, S$, the number $N$ between two reference lines $a, b$, distance $d$ apart, ruled on the bottom surface of $V$, is determined. The corresponding distances $D$ and $d$ are known, therefore the difference in elevation of the zero position and any other position of $F$ is equal to $\frac{\lambda D N}{2 d}$. The distance $d$ is made such that $\frac{\lambda D N}{2 d}=\frac{N}{2} \mu$. The number $N$ can be determined with an uncertainty of not more than 0.1 of a band, therefore the change in elevation of the contact point $F$ can be determined with an uncertainty of not more than $0.05 \mu$.

A standard $0.1 \mathrm{~mm}$ cell which has been calibrated by another interference method with an uncertainty of not more than $0.01 \mu$ is used to set the zero position of the contact point $F$.

In using the instrument the supporting surfaces of the haemacytometer are placed on the contact surfaces $H, H$ of the anvil, with the contact point $F$ touching the center of the ruled portion of the central strip $C$. A small weight $R$ is placed on the chamber to insure constant pressure. The fringes between the reference marks $a$ and $b$ are then counted. Since each fringe denotes a displacement of $0.5 \mu$ of the contact point $F$ from its zero position, four fringes denote that. the depth of the haemacytometer is in error by $2 \mu$, which is the tolerance limit. If there are more than four fringes in the distance $d$, the chamber is rejected. Whether the chamber is too deep or too shallow can be readily determined.

\section{TEST OF THE COVER GLASSES}

The method commonly used for testing the planeness of optical surfaces ${ }^{1}$ is used in testing the planeness of the cover glasses. The corer glass $D$ is placed on a test plate $K$ (fig. 7 ) so that a thin wedgeshaped film is formed between them. When viewed with the optical arrangement described in the preceding section of this paper, a system of interference fringes is seen across the cover glass. If the fringes are straight, parallel, and equally spaced the surface of the cover glass is plane. If the surface is not plane, the fringes will be curved and will deviate from a straight reference line $J$ by as many times the distance between any two adjacent fringes, as the cover glass surface deviates by $\frac{\lambda}{2}$ from a true plane. 
Since the tolerance in planeness of the surface of cover glasses is $0.002 \mathrm{~mm}$, which is equal to about four wave lengths of the yellow
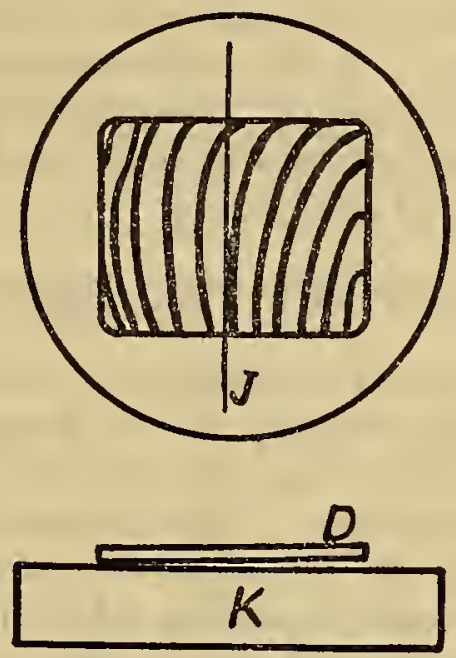

Fig. 7.-Test of planeness of cover glasses

light from helium, a curvature in the fringes amounting to more than eight fringe spacings rejects the cover glass.

\section{TEST FOR PLANENESS AND PARALLELISM OF THE CENTRAL AND SUPPORTING SURFACES}

A test plate $K$ (fig. 8) is brought into close contact with the two supporting surfaces of the haemacytometer, and the interference fringes, due to the light reflected from the lower surface of the test
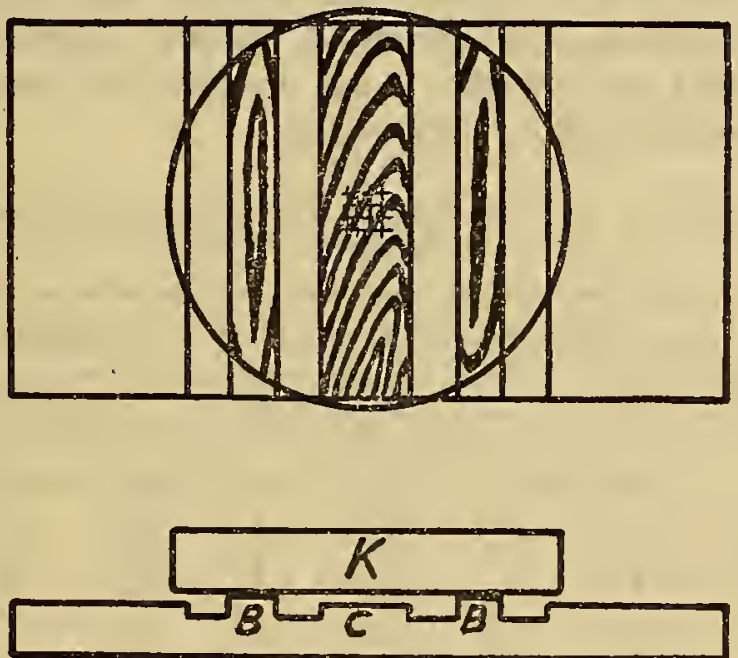

FIG. 8.-Test of planeness and parallelism of the central and supporting surfaces of haemacytometers

plate and the upper surface of the central strip $C$ are observed with the viewing apparatus previously described in Section V. If the surface of the central strip is plane and parallel to the plane of the 
supporting surfaces, uniform light or darkness will be seen across the strip. If the surface of the strip is plane and makes an angle with the other surfaces, a system of straight and equally spaced fringes will be seen across the strip. If the surface of the central strip is not plane, the fringes will be unequally spaced and eurved. The amount of irregularity in the surfaces can be determined from the number of fringes, their spacing, and curvature.

\section{TEST OF THE TWO INSTRUMENTS}

In order to test the speed of operation of the two instruments and the reproducibility and accuracy of the measurements made with them, four observers made measurements on 48 different haemacytometers with both instruments. The first two observers (see Table 1) had used the micrometric apparatus for several years but were unfamiliar with interference apparatus, while the other two observers had never before used the micrometric instrument but were experienced in the use of interferometers.

The supporting surfaces and central strip of all chambers were first tested for planeness and parallelism. The surfaces of the supporting strips were found to be plane within 0.1 to $0.2 \mu$. The surface of the central strip of some of the haemacytometers was found to be plane, and parallel to the supporting surfaces within 0.2 to $0.3 \mu$. Others, however, were either cylindrical or made a considerable angle with the supporting surfaces. These imperfections caused, in some cases, variations of more than $5.0 \mu$ in the depth across the strip and $0.6 \mu$ across the ruled square millimeter. In testing imperfect chambers of this kind it is impossible for any instrument to repeat its reading exactly or to within $0.1 \mu$ because the same point on the chamber can not be located repeatedly.

$\mathrm{T}_{\mathrm{ABLE}}$ 1.-Difference in microns between two separate determinations on each chamber

\begin{tabular}{|c|c|c|c|c|c|c|c|c|}
\hline \multirow{2}{*}{ Chamber No. } & \multicolumn{4}{|c|}{ Micrometer observers } & \multicolumn{4}{|c|}{ Interferometer observers } \\
\hline & B. L. P. & M. P. M. & C. G.P. & a. E.M. & B. L.P. & M.P.M. & C. a.P. & a. E.M. \\
\hline & $\begin{array}{r}0.5 \\
.4 \\
.2 \\
.0 \\
.1\end{array}$ & $\begin{array}{l}0.0 \\
.0 \\
.3 \\
.1 \\
.4\end{array}$ & $\begin{array}{l}0.1 \\
.2 \\
.0 \\
.1 \\
.0\end{array}$ & $\begin{array}{r}3.9 \\
.3 \\
.1 \\
.1 \\
.0\end{array}$ & $\begin{array}{r}0.10 \\
.00 \\
.10 \\
.30 \\
.05\end{array}$ & $\begin{array}{l}0.00 \\
.10 \\
.05 \\
.00 \\
.10\end{array}$ & $\begin{array}{l}0.05 \\
.00 \\
.00 \\
.00 \\
.10\end{array}$ & $\begin{array}{l}0.05 \\
.00 \\
.00 \\
.05 \\
.05\end{array}$ \\
\hline $\begin{array}{l}6 \\
6 \\
8 \\
8 \\
9 \\
10\end{array}$ & $\begin{array}{l}.0 \\
.3 \\
.3 \\
.3 \\
.5\end{array}$ & $\begin{array}{l}.2 \\
.2 \\
.4 \\
.3 \\
.1\end{array}$ & $\begin{array}{l}.4 \\
.0 \\
.0 \\
.2 \\
.0\end{array}$ & $\begin{array}{l}.3 \\
.2 \\
.1 \\
.0 \\
.1\end{array}$ & $\begin{array}{l}.10 \\
.05 \\
.30 \\
.10 \\
.00\end{array}$ & $\begin{array}{l}.05 \\
.10 \\
.00 \\
.20 \\
.15\end{array}$ & $\begin{array}{l}.05 \\
.00 \\
.00 \\
.15 \\
.15\end{array}$ & $\begin{array}{l}.15 \\
.05 \\
.05 \\
.00 \\
.00\end{array}$ \\
\hline $\begin{array}{l}11 \\
12 \\
13 \\
14 \\
15\end{array}$ & $\begin{array}{l}.0 \\
.1 \\
.1 \\
.2 \\
.4\end{array}$ & $\begin{array}{l}.1 \\
.1 \\
.3 \\
.0 \\
.1\end{array}$ & $\begin{array}{l}.3 \\
.1 \\
.1 \\
.2 \\
.3\end{array}$ & $\begin{array}{r}.4 \\
1.9 \\
.2 \\
.1 \\
.1\end{array}$ & $\begin{array}{l}.15 \\
.10 \\
.00 \\
.10 \\
.20\end{array}$ & $\begin{array}{l}.20 \\
.15 \\
.05 \\
.20 \\
.05\end{array}$ & $\begin{array}{l}.15 \\
.05 \\
.05 \\
.05 \\
.00\end{array}$ & $\begin{array}{l}.00 \\
.00 \\
.05 \\
.05 \\
.00\end{array}$ \\
\hline
\end{tabular}


TABLE 1.-Difference in microns between two separate determinations on each chamber-Continued

\begin{tabular}{|c|c|c|c|c|c|c|c|c|}
\hline \multirow{2}{*}{ Chamber No. } & \multicolumn{4}{|c|}{ Micrometer observers } & \multicolumn{4}{|c|}{ Interferometer observers } \\
\hline & B. L. P. & M. P.M. & C G.P. & G. E. M. & B. L. P. & M. P. M. & C. G. P. & G. E.M. \\
\hline $\begin{array}{l}16 \\
17 \\
18 \\
19 \\
20\end{array}$ & $\begin{array}{r}0.1 \\
.1 \\
.1 \\
.1 \\
.1\end{array}$ & $\begin{array}{l}0.5 \\
.1 \\
.2 \\
.1 \\
.0\end{array}$ & $\begin{array}{r}0.1 \\
.1 \\
.1 \\
.0 \\
.4\end{array}$ & $\begin{array}{r}0.1 \\
3.5 \\
.0 \\
.2 \\
.1\end{array}$ & $\begin{array}{r}0.10 \\
.20 \\
.20 \\
.20 \\
.00\end{array}$ & $\begin{array}{r}0.05 \\
.25 \\
.25 \\
.00 \\
.60\end{array}$ & $\begin{array}{l}0.20 \\
.05 \\
.00 \\
.05 \\
.00\end{array}$ & $\begin{array}{l}0.05 \\
.05 \\
.00 \\
.10 \\
.10\end{array}$ \\
\hline $\begin{array}{l}21-\cdots \\
22-\cdots \\
23-\cdots \\
24-\cdots \\
25-\cdots\end{array}$ & $\begin{array}{l}.0 \\
.0 \\
.1 \\
.0 \\
.3\end{array}$ & $\begin{array}{l}.2 \\
.3 \\
.1 \\
.2 \\
.1\end{array}$ & $\begin{array}{l}.0 \\
.1 \\
.6 \\
.2 \\
.2\end{array}$ & $\begin{array}{r}.3 \\
.2 \\
1.4 \\
2.6 \\
.1\end{array}$ & $\begin{array}{l}.10 \\
.10 \\
.10 \\
.05 \\
.05\end{array}$ & $\begin{array}{l}.15 \\
.05 \\
.00 \\
.00\end{array}$ & $\begin{array}{l}.30 \\
.15 \\
.00 \\
.00 \\
.00\end{array}$ & $\begin{array}{l}.00 \\
.00 \\
.05 \\
.05 \\
.05\end{array}$ \\
\hline $\begin{array}{l}26 \ldots \\
27-\ldots \\
28 \\
29-\ldots \\
30 \ldots-\end{array}$ & $\begin{array}{l}.2 \\
.2 \\
.2 \\
.0 \\
.4\end{array}$ & $\begin{array}{l}.1 \\
.7 \\
.5 \\
.1 \\
.3\end{array}$ & $\begin{array}{l}.2 \\
.3 \\
.2 \\
.3 \\
.0\end{array}$ & $\begin{array}{l}.1 \\
.2 \\
.3 \\
.9 \\
.4\end{array}$ & $\begin{array}{l}.00 \\
.00 \\
.15 \\
.45 \\
.20\end{array}$ & $\begin{array}{l}.00 \\
.10 \\
.40 \\
.10 \\
.10\end{array}$ & $\begin{array}{l}.15 \\
.00 \\
.05 \\
.05 \\
.10\end{array}$ & $\begin{array}{l}.05 \\
.30 \\
.30 \\
.05 \\
.05\end{array}$ \\
\hline 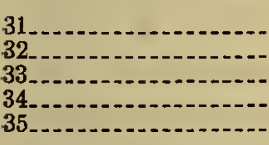 & $\begin{array}{l}.4 \\
.5 \\
.2 \\
.2 \\
.4\end{array}$ & $\begin{array}{l}.7 \\
.0 \\
.4 \\
.1 \\
.1\end{array}$ & $\begin{array}{r}.2 \\
.6 \\
.3 \\
1.5 \\
.3\end{array}$ & $\begin{array}{r}.0 \\
.1 \\
2.7 \\
1.0 \\
.4\end{array}$ & $\begin{array}{l}.05 \\
.10 \\
.05 \\
.20 \\
.05\end{array}$ & $\begin{array}{l}.10 \\
.60 \\
.10 \\
.20 \\
.00\end{array}$ & $\begin{array}{l}.15 \\
.05 \\
.10 \\
.10 \\
.20\end{array}$ & $\begin{array}{l}.10 \\
.00 \\
.05 \\
.15 \\
.15\end{array}$ \\
\hline $\begin{array}{l}36 \\
37 \\
38 \\
39 \\
40\end{array}$ & $\begin{array}{l}.4 \\
.0 \\
.4 \\
.2 \\
.3\end{array}$ & $\begin{array}{l}.6 \\
.3 \\
.3 \\
.5 \\
.0\end{array}$ & $\begin{array}{l}.2 \\
.4 \\
.4 \\
.1 \\
.1\end{array}$ & $\begin{array}{r}.8 \\
1.0 \\
.4 \\
.4 \\
.1\end{array}$ & $\begin{array}{l}.05 \\
.00 \\
.00 \\
.00 \\
.00\end{array}$ & $\begin{array}{l}.20 \\
.10 \\
.20 \\
.10 \\
.00\end{array}$ & $\begin{array}{l}.05 \\
.05 \\
.00 \\
.15 \\
.00\end{array}$ & $\begin{array}{l}.10 \\
.05 \\
.05 \\
.10 \\
.00\end{array}$ \\
\hline 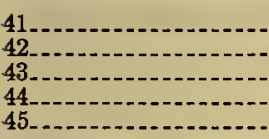 & $\begin{array}{l}.0 \\
.2 \\
.0 \\
.2 \\
.0\end{array}$ & $\begin{array}{l}.5 \\
.2 \\
.1 \\
.1 \\
.5\end{array}$ & $\begin{array}{l}.2 \\
.2 \\
.2 \\
.1 \\
.4\end{array}$ & $\begin{array}{r}.3 \\
.2 \\
.2 \\
.4 \\
2.1\end{array}$ & $\begin{array}{l}.05 \\
.10 \\
.10 \\
.10 \\
.10\end{array}$ & $\begin{array}{l}.10 \\
.00 \\
.00 \\
.00 \\
.10\end{array}$ & $\begin{array}{l}.05 \\
.05 \\
.10 \\
.05 \\
.10\end{array}$ & $\begin{array}{l}.05 \\
.05 \\
.00 \\
.00 \\
.20\end{array}$ \\
\hline 476 & $\begin{array}{l}.3 \\
.3 \\
.1\end{array}$ & $\begin{array}{l}.2 \\
.2 \\
.2\end{array}$ & $\begin{array}{l}.2 \\
.0 \\
.4\end{array}$ & $\begin{array}{r}1.1 \\
.2 \\
.0\end{array}$ & $\begin{array}{l}.15 \\
.05 \\
.10\end{array}$ & $\begin{array}{l}.10 \\
.20 \\
.10\end{array}$ & $\begin{array}{l}.00 \\
.05 \\
.05\end{array}$ & $\begin{array}{l}.05 \\
.00 \\
.00\end{array}$ \\
\hline Maximum & $\begin{array}{l}.5 \\
.2\end{array}$ & .7 & $\begin{array}{r}1.5 \\
.2\end{array}$ & $\begin{array}{r}3.9 \\
.6\end{array}$ & $\begin{array}{l}.45 \\
.10\end{array}$ & $\begin{array}{l}.60 \\
.12\end{array}$ & $\begin{array}{l}.30 \\
.07\end{array}$ & .30 \\
\hline $\begin{array}{l}\text { Number larger than } \\
0.3 \mu \text { (in minutes) } \\
\text { Time (in }\end{array}$ & $\begin{array}{r}10 \\
384\end{array}$ & $\begin{array}{r}11 \\
402\end{array}$ & $\begin{array}{r}9 \\
451\end{array}$ & $\begin{array}{r}18 \\
640\end{array}$ & $\begin{array}{r}1 \\
105\end{array}$ & $\begin{array}{r}3 \\
122\end{array}$ & $\begin{array}{r}0 \\
111\end{array}$ & $\begin{array}{r}0 \\
171\end{array}$ \\
\hline
\end{tabular}

To test the reproducibility of measurements of the instruments under actual test conditions, each haemacytometer was measured twice with each machine by the different observers. In Table 1, column 1, are given the designation numbers of the chambers and the remaining columns give the differences in microns in the duplicate readings of the depth of each haemacytometer. At the bottom of each column are given the observers maximum difference in duplicate measurements and the mean of all the differences in the duplicate measurements. The maximum differences with the micrometer instrument are from 2 to 13 times those with the interferometer, the mean differences are from 2 to 10 times those of the interferometer. Part of these differences in duplicate readings may be due to the imperfections in the surfaces of the central strips which caused variations in the depths across the ruled square millimeter. It was impossible to locate exactly the same point in the 
square each time, therefore two measurements made with a perfect instrument on an imperfect chamber might differ by $0.5 \mu$. With this set of haemacytometers the variation in measurement due to this cause should not be more than 0.3 to $0.5 \mu$. Larger differences are due to observational errors or unreliability of the measuring instrument. The number of differences that are greater than $0.3 \mu$ obtained by each observer and the time required to make a complete set of observations are shown below the mean differences. There are four differences greater than $0.3 \mu$ with the interferometer, and 48 with the micrometric instrument. From these results it is seen that the size of the variations in the means obtained with the micrometric apparatus are about three times those obtained with the interferometer, and the number of large variations of $0.5 \mu$ or more is many times greater. The time required to make one measurement of the depth of a chamber with the micrometric instrument is about four or five times that required when the interferometer is used. Heretofore in calibrating chambers at the Bureau of Standards, the large variations between individual observations with the micrometric apparatus, have necessitated the taking of a large number of duplicate measurements on each chamber. With the interference apparatus, the consistency of the observations show that two or three should be sufficient, thereby greatly reducing the time consumed in calibration, which is one of the principal advantages of the new instrument.

To test the accuracy of the machine in measuring high-quality chambers, 10 were selected that had very nearly perfect surfaces. The depths of these at the center of the millimeter square were measured by means of an interference method which gave the correct depth within about $0.03 \mu$. Each of the 10 chambers was then measured by each observer on both machines. The differences between the value of the depth measured with the instruments and those obtained by the precise method are given in Table 2. In column 1 are given the designation numbers of the chambers, in column 2 the variation in depth of the chamber at different parts of the millimeter square, and in the remaining columns the errors in the measured depths of the chambers. 
TABLE 2.-Errors in microns in measurement of the depths of high-quality chambers

\begin{tabular}{|c|c|c|c|c|c|c|c|c|c|}
\hline \multirow{2}{*}{ aamber No. } & \multirow{2}{*}{$\begin{array}{l}\text { Yaria- } \\
\text { tion in } \\
\text { depth } \\
\text { across } \\
\text { the } \\
\text { milli- } \\
\text { meter } \\
\text { square }\end{array}$} & \multicolumn{4}{|c|}{ Micrometer observers } & \multicolumn{4}{|c|}{ Interferometer observers } \\
\hline & & B.L.P. & M.P.M & C. G.P. & G.E.M. & B.L.P. & M.P.M. & O. G.P. & G. E.M. \\
\hline $\begin{array}{l}17 \ldots \ldots \\
18 . \ldots . \\
23 . . .\end{array}$ & $\begin{array}{l}0.2 \\
.2 \\
.2 \\
.2 \\
.3\end{array}$ & $\begin{array}{r}1.1 \\
.6 \\
1.0 \\
1.0 \\
.1\end{array}$ & $\begin{array}{l}0.8 \\
.9 \\
.8 \\
.9 \\
.1\end{array}$ & $\begin{array}{r}0.8 \\
.9 \\
1.0 \\
1.1 \\
.2\end{array}$ & $\begin{array}{r}3.1 \\
1.1 \\
.6 \\
.5 \\
.1\end{array}$ & $\begin{array}{l}0.04 \\
.03 \\
.02 \\
.03 \\
.34\end{array}$ & $\begin{array}{l}0.81 \\
.12 \\
.10 \\
.13 \\
.01\end{array}$ & $\begin{array}{l}0.07 \\
.03 \\
.01 \\
.01 \\
.14\end{array}$ & $\begin{array}{l}0.18 \\
.27 \\
.24 \\
.34 \\
.06\end{array}$ \\
\hline $\begin{array}{l}24 \\
33 \\
34 \\
35 \\
35\end{array}$ & $\begin{array}{l}.3 \\
.0 \\
.0 \\
.3 \\
.3\end{array}$ & $\begin{array}{l}.7 \\
.0 \\
.5 \\
.9 \\
.4\end{array}$ & $\begin{array}{l}1.0 \\
.4 \\
.4 \\
.9 \\
.9\end{array}$ & $\begin{array}{l}.9 \\
.4 \\
.0 \\
.7 \\
.6\end{array}$ & $\begin{array}{r}.1 \\
.8 \\
1.2 \\
1.2 \\
.9\end{array}$ & $\begin{array}{l}.18 \\
.00 \\
.05 \\
.04 \\
.04\end{array}$ & $\begin{array}{l}.06 \\
.03 \\
.08 \\
.26 \\
.14\end{array}$ & $\begin{array}{l}.09 \\
.07 \\
.07 \\
.03\end{array}$ & $\begin{array}{l}.02 \\
.05 \\
.21 \\
.28 \\
.21\end{array}$ \\
\hline $\begin{array}{l}\text { Maximum } \\
\text { Mean.-- }\end{array}$ & -....... & $\begin{array}{r}1.1 \\
.6\end{array}$ & $\begin{array}{r}1.0 \\
.7\end{array}$ & $\begin{array}{r}1.1 \\
.7\end{array}$ & $\begin{array}{l}3.1 \\
1.0\end{array}$ & .34 & .81 & $\begin{array}{l}.16 \\
.07\end{array}$ & $\begin{array}{l}.34 \\
.19\end{array}$ \\
\hline
\end{tabular}

The maximum errors with the micrometric apparatus range from 1.0 to $3.0 \mu$ and the mean error from 0.6 to $1.0 \mu$ for the different observers. With the interference apparatus the maximum errors range from 0.2 to $0.8 \mu$ and the mean errors from 0.07 to $0.17 \mu$. This shows that in measuring high-quality chambers the average error with the interferometer is only about one-fifth as large as the error with the micrometric apparatus.

To show the effect of imperfect haemacytometers on the performance of the two instruments, 12 chambers were selected that had irregularities in the surface of the central strip sufficient to give variation in depth across the millimeter square of from 0.2 to $0.7 \mu$. The results of measurement similar to those shown for the preceding set are given in Table 3 . With the micrometric instrument the maximum and mean errors are practically the same as those for the better grade of chambers. This shows that the instrumental errors are large enough so that slight imperfections in a chamber have little effect in the final result. With the interference instrument the maximum and mean errors for the imperfect chambers are about twice as great as, or about $0.2 \mu$ larger than, the errors for the better grade. This shows that the interference method is sufficiently sensitive to detect slight variations in depth across the millimeter square and that irregularities of $0.3 \mu$ in the surface of the ruled square have an appreciable effect on the measurements. 
TABLE 3.-Errors in microns in measurement of the depth of imperfect chambers

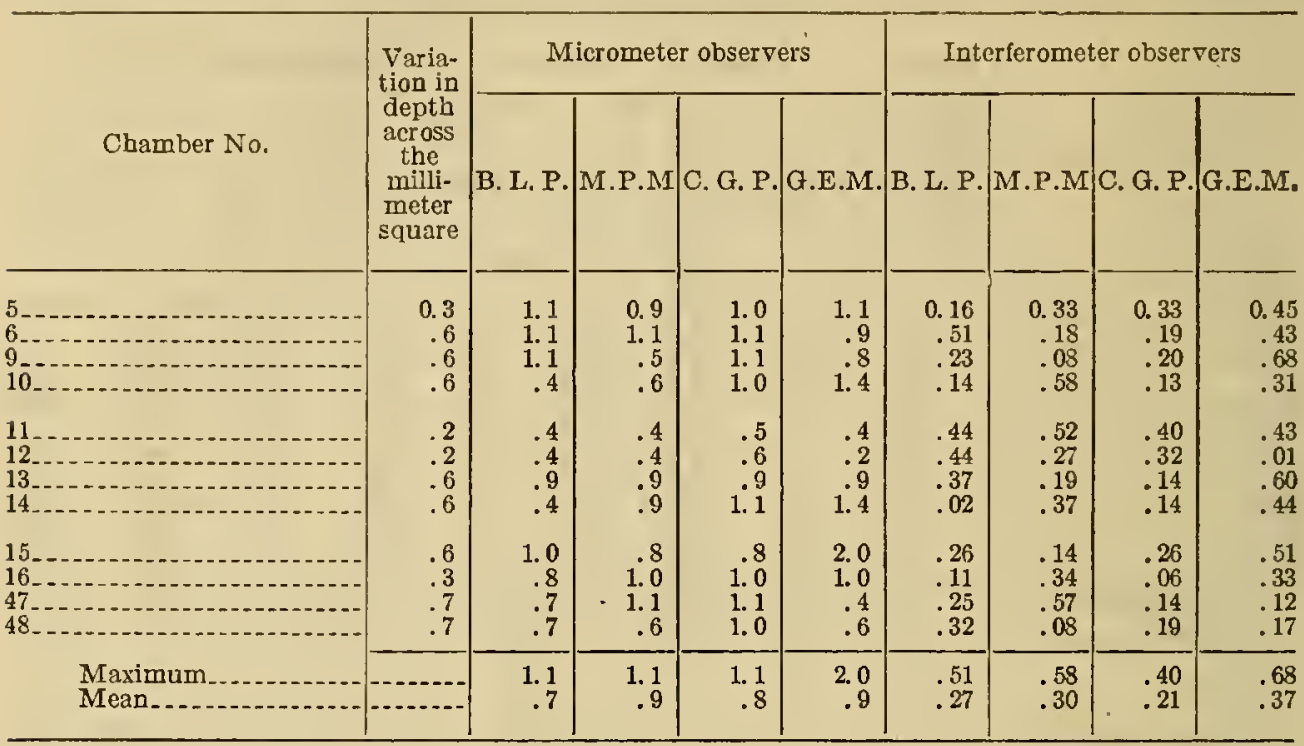

To further test the accuracy and reproducibility of the measurements made with the interference instrument, the best 12 of the 48 chambers were selected and measured. The surface errors in the first 6 were less than $0.1 \mu$ and in the last 6 about $0.2 \mu$. Each chamber was measured four times by each observer. The first column of Table 4 gives the designation numbers of the chambers, the second the surface error, and the remaining columns the errors in the measured depths. These results show that when measurements are made with the interference instrument on chambers having very plane surfaces the results are reproducible and accurate within 0.1 to $0.2 \mu$.

TABLE 4.-Reproducibility and accuracy of measurements made with the interference instrument

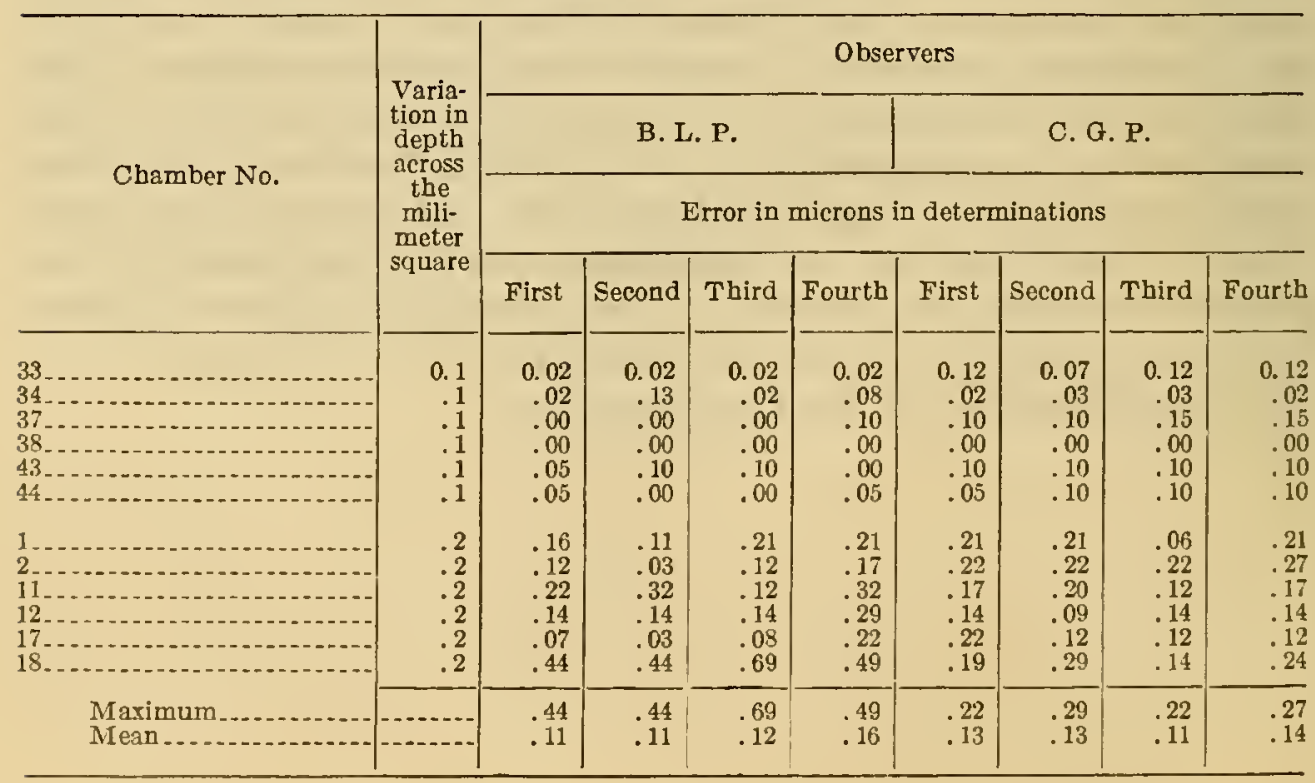


To further test the relative accuracy of the two instruments measurements were made on the most perfect chamber of the group of 48. Each of two observers measured the depth of the chamber 10 times with the micrometric instrument and 6 times with the interferometer. The errors of the measurements are given in Table 5, and show that with the micrometer, individual measurements upon the same sample may differ by $1 \mu$ and that the mean of 10 measurements may be in error by $1.0 \mu$. None of the measurements made with the interferometer was in error by more than $0.1 \mu$.

TABLE 5.-Errors in microns in the repeated measurements in the depth of chamber No. 38

\begin{tabular}{|c|c|c|c|}
\hline \multicolumn{2}{|c|}{ Micrometer observer } & \multicolumn{2}{|c|}{ Interferometer obser ver } \\
\hline B. L.P. & C. G. P. & B. L. P. & C. G.P. \\
\hline $\begin{array}{r}0.7 \\
1.1 \\
.7 \\
1.8 \\
1.5 \\
.9 \\
1.1 \\
.8 \\
1.2 \\
1.8\end{array}$ & $\begin{array}{l}1.0 \\
.5 \\
.7 \\
.4 \\
.6 \\
.8 \\
.7 \\
.6 \\
.5 \\
.6\end{array}$ & $\begin{array}{l}0.00 \\
.00 \\
.00 \\
.00 \\
.05 \\
.05 \\
.0 \\
\\
\\
\end{array}$ & $\begin{array}{r}0.00 \\
.00 \\
.00 \\
.00 \\
.10 \\
.10\end{array}$ \\
\hline $\begin{array}{l}\text { Maximum } 1.8 \\
\text { Mean_-_1.2 }\end{array}$ & $\begin{array}{r}1.0 \\
.6\end{array}$ & $\begin{array}{l}.05 \\
.02\end{array}$ & $\begin{array}{l}.10 \\
.03\end{array}$ \\
\hline
\end{tabular}

\section{CONCLUSION}

The extensive use of haemacytometers and the importance of having them accurate in order to insure a reliable count of the number of corpuscles in the blood have created a need for more rapid and precise methods for testing their dimensions and for a more reliable measuring instrument. The micrometric apparatus commonly used to test the depths of haemacytometers requires several measurements by different observers to eliminate the possibility of intolerable errors (which for a single observation might be more than a micron). Methods which make use of the interference of light waves were, therefore, used in making the measurements. With the interference apparatus illustrated and described in this article the planeness of the cover plates and the planeness and parallelism of the surfaces of the supporting and central strips of the chambers can be measured with an uncertainty of not more than a few hundredths of a micron. The results of comparative tests of the speed, reliability and accuracy of the micrometric and interference instruments given in the tables show that the uncertainty of the micrometric measurements is about $1 \mu$ while the uncertainty of the interference method 
is not more than $0.2 \mu$. The average time required to measure a chamber is five minutes with the micrometric instrument and about one minute with the interference instrument. With the latter instrument any defect can be readily detected and located, and any error in the dimensions can be quickly measured. This should lead to improvement in the quality of the chambers and a corresponding increase in the percentage conforming to the specifications.

Washington, March 7. 1925. 